\title{
Central pontine myelinolysis without hyponatraemia
}

\author{
${ }^{1} \mathrm{P}$ Bose, ${ }^{2} \mathrm{~A}$ Kunnacherry, ${ }^{3} \mathrm{P}$ Maliakal \\ ${ }^{1}$ Specialty Registrar in Neurology; ${ }^{2}$ Locum Consultant Neurologist; ${ }^{3}$ Consultant Neuroradiologist; Hull Royal Infirmary, Hull, UK
}

\begin{abstract}
A 55-year-old woman with a history of excess alcohol intake presented to the acute medical unit following concerns regarding her electrolyte disturbances. During correction of the electrolytes, the patient developed central pontine myelinolysis. The unusual features in the case were the absence of hyponatraemia which is usually associated with central pontine myelinolysis and also the good recovery that the patient made. Looking at the electrolyte changes, we suspect there may be a link to the rapid osmotic shifts occurring during refeeding and central pontine myelinolysis.
\end{abstract}

Correspondence to $P$ Bose, Apartment 38, Aruba, Gotts Road, Leeds LSI 2 IDW, UK

tel. $+44(0) / 482674235$ e-mail dr_pyari@yahoo.com

KEYWORDS Central pontine myelinolysis, refeeding syndrome, coma, rehabilitation

DECLARATION OF INTERESTS No conflicts of interest declared.

\section{CASE REPORT}

A 55-year-old woman with a history of excess alcohol intake presented to the acute medical unit. The patient usually consumed about four bottles of wine a day and according to her partner, over the month prior to admission, she had an alcohol binge, eating very little food. Two weeks prior to admission the patient tried to reduce her drinking and developed four generalised tonic-clonic seizures. She became progressively lethargic. Her GP arranged blood tests and then sent her immediately to hospital when the tests showed potassium of $1.9 \mathrm{mmol} / \mathrm{L}(\mathrm{n}=3.5-5)$ and magnesium of $0.56 \mathrm{mmol} / \mathrm{L}(\mathrm{n}=0.7-\mathrm{I})$. The sodium was normal (I 35 $\mathrm{mmol} / \mathrm{L})$. On the day of hospital admission, the patient was alert and orientated to time, place and person. She was afebrile with a pulse rate of 60 per minute in sinus rhythm and her blood pressure was 76/50. There was no neurological deficit. The blood sugar using test strips was 9.I. The patient's ECG on admission (Figurel) showed changes suggestive of hypokalaemia.

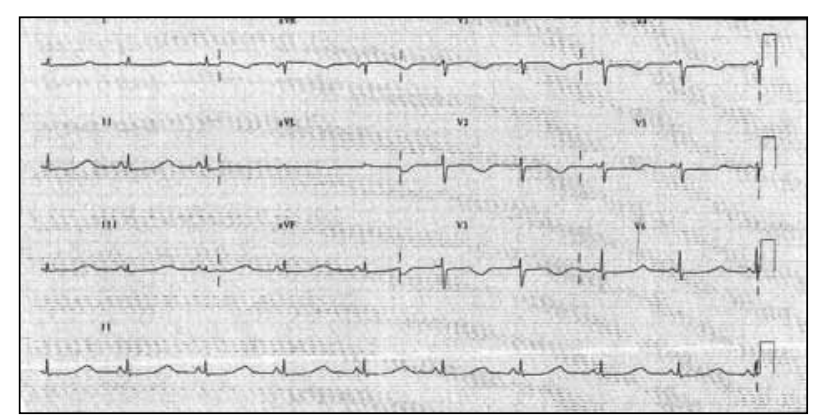

FIGURE I Electrocardiogram (ECG) on admission. ECG showing $\mathrm{T}$ inversion $\mathrm{VI}$ to $\mathrm{V} 4$ and prolongation of $\mathrm{QT}$ suggestive of hypokalaemia, but hypomagnesaemia can also cause similar changes. Measured heart rate was 54 beats per minute, PR interval I $32 \mathrm{~ms}$, corrected QT interval $428 \mathrm{~ms}$.

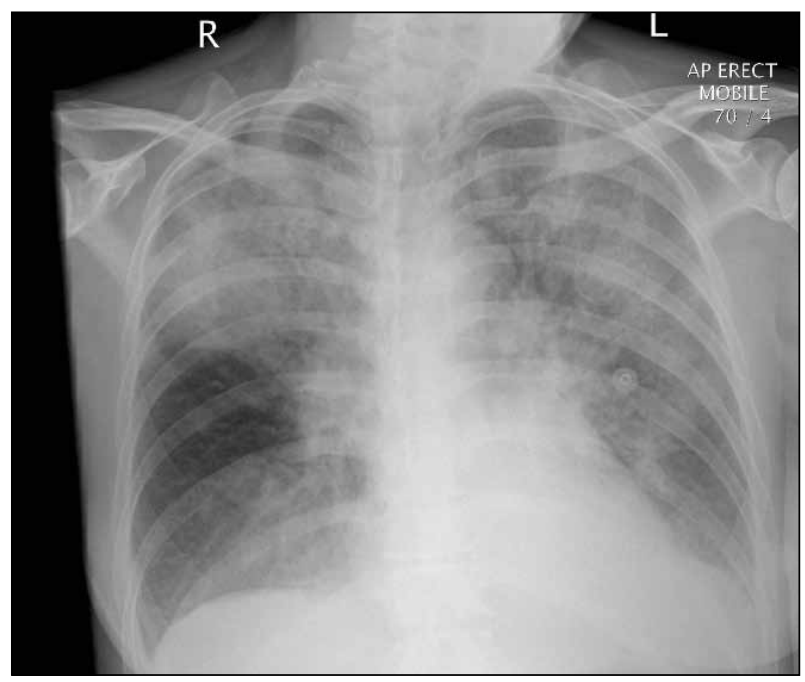

FIGURE 2 Chest X-ray on day two showing right upper zone consolidation.

The medical team decided to aggressively treat the electrolyte disturbances. The patient was given intravenous fluids with potassium and magnesium and calcium replacement along with thiamine. The following day, the electrolytes were repeated and it showed that the potassium had gone up to 2.7. The magnesium was normal (0.80) and so was the sodium (135). However, the patient started getting confused and disorientated. The oxygen saturations dropped and the patient required supplemental oxygen. A chest $X$-ray showed a new right upper zone consolidation. The patient was promptly started on antibiotics for pneumonia (Figure 2).

In the early hours of the third day, the patient's oxygen saturations dropped to $80 \%$ on $60 \%$ oxygen. A crash call was put out by the ward staff. The patient was drowsy and confused. The blood sugar on testing strips had dropped to 2.5 and the patient was given intravenous 


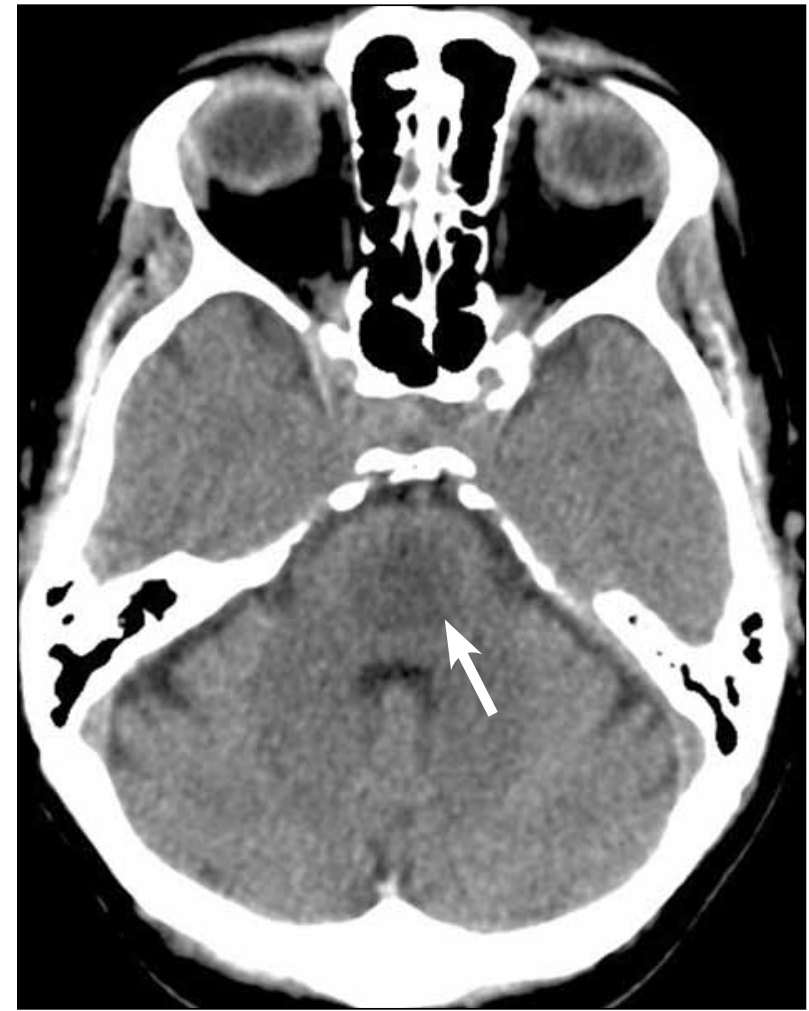

FIGURE 3 Computerised tomography (CT) scan of head.A large area of reduced attenuation centrally within the pons raising the possibility of central pontine myelinolysis.

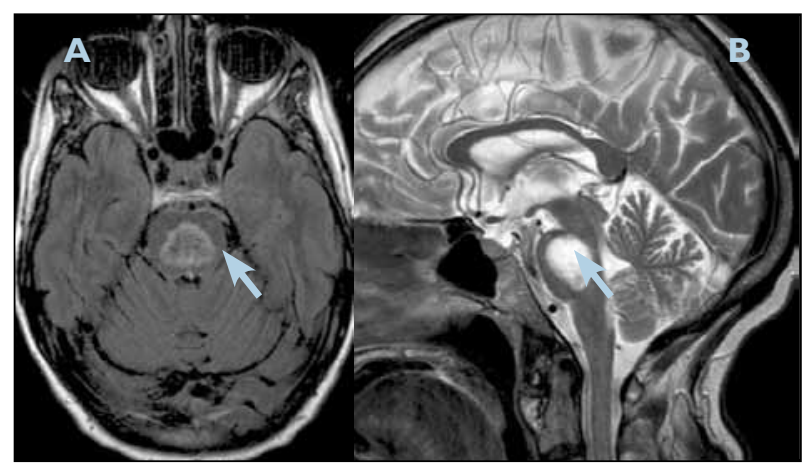

FIGURE $4 \mathrm{~A}$ and $\mathrm{B}$ Magnetic resonance imaging (MRI) scans confirming the diagnosis of central pontine myelinolysis showing the increased T2 weighted signal in the central pons.*

dextrose. At this stage the diagnosis was not completely clear but she was intubated and ventilated for a presumed diagnosis of worsening pneumonia. A computerised tomography (CT) scan of the chest confirmed a chest infection with no evidence of a pulmonary embolism. As the patient was still drowsy and confused despite two days of intravenous antibiotics, a CT scan of the head (Figure 3) was arranged. This showed a large area of reduced attenuation centrally within the pons, raising the possibility of central pontine myelinolysis.
A neurology consultation was sought. The patient was tubed and under mild sedation by the time the neurology registrar arrived. On examination, the pupils were pinpoint but reacting. The patient was opening and closing her eyes to command and had flaccid quadriparesis with a flicker of movement in the right hand. The plantar reflexes were equivocal. Speech and mental status could not be assessed because of the endotracheal tube. This was clinically suggestive of a locked-in state.The differentials considered at this stage were central pontine myelinolysis (though the patient had normal sodium) and brainstem encephalitis. A lumbar puncture was performed and the result was completely normal, ruling out brainstem encephalitis. Existing literature does recognise that rapid correction of low sodium is not the sole cause of central pontine myelinolysis. The neurology team arranged a magnetic resonance imaging (MRI) scan to confirm central pontine myelinolysis and observed the patient for signs of improvement. The next day the patient started showing signs of improvement. She was still tubed but breathing spontaneously, and was now localising to pain with both arms. She was able to move both lower limbs but was still weak with brisk reflexes with a sustained left ankle clonus, suggesting a spastic quadriparesis. The dietician was involved and the patient received nasogastric feeds and concurrent correction of all electrolyte deficits as per the existing feeding guidelines. ${ }^{1,2}$

Eventually transferred to the neurology ward, the patient underwent physiotherapy. She became independently mobile and was communicating well. An MRI scan of the brain done while the patient was on the ward was in keeping with central pontine myelinolysis with a degree of extrapontine myelinolysis (Figure 4). On day 37 postadmission, the patient was discharged after making a remarkable recovery, with outpatient follow-up planned.

\section{DISCUSSION}

Central pontine myelinolysis was first described by Adams et al in 1958 as a clinicopathological entity. ${ }^{3}$ The original paper described four cases with fatal outcomes, and the findings on autopsy. The aetiology was not known then but the authors suspected the cause to be either a toxin or a nutritional deficiency. 'Central pontine' indicated the site of the lesion and 'myelinolysis' was used to emphasise that myelin was affected preferentially compared to the other neuronal elements. The authors intentionally avoided the term 'demyelination' to describe the condition, in order to differentiate the pathology of this condition from multiple sclerosis and other neuroinflammatory disorders in which myelin loss is associated with inflammation. In 1983, Laureno et al suggested rapid correction of hyponatraemia as the cause for the condition, based on experimental data on animal models. They suggested that the condition could be prevented by correcting hyponatraemia by less than $10 \mathrm{mmol} / \mathrm{L}$ in 24 hours. 
TABLE I The hypokalaemia, hypomagnesaemia, hypocalcaemia on admission is suggestive of malnutrition

The patient had a fall in serum phosphate on day five, fall in serum potassium on day two following admission. Also from the admission notes, the blood sugar on testing strips had dropped from 9.1 on admission to 2.5 on day three. All these electrolyte shifts can be explained by the 'insulin surge' associated with refeeding syndrome. ${ }^{6}$

\begin{tabular}{|c|c|c|c|c|c|c|c|c|c|}
\hline & DI & D2 & D3 & D4 & D5 & D7 & DIO & DII & D29 \\
\hline $\begin{array}{l}\text { Sodium } \\
\text { (range } 135-144 \mathrm{mmol} / \mathrm{L} \text { ) }\end{array}$ & 135 & 135 & $14 \mid$ & 144 & I $47(\mathrm{H})$ & $\mathrm{I} 45(\mathrm{H})$ & $\mathrm{I} 46(\mathrm{H})$ & 142 & 139 \\
\hline $\begin{array}{l}\text { Potassium } \\
\text { (range } 3.5-5.3 \mathrm{mmol} / \mathrm{L} \text { ) }\end{array}$ & $1.9(\mathrm{~L})$ & $1.8(\mathrm{~L})$ & 2.5 & 4.4 & 4.5 & 4.3 & 3.9 & 4.4 & 3.8 \\
\hline $\begin{array}{l}\text { Magnesium } \\
\text { (range } 0.7-1 \mathrm{mmol} / \mathrm{L})\end{array}$ & $56(\mathrm{~L})$ & 0.80 & 0.81 & 0.98 & I.0I $(\mathrm{H})$ & NA & 0.76 & 0.73 & NA \\
\hline $\begin{array}{l}\text { Phosphate } \\
\text { (range } 0.7-1.5 \mathrm{mmol} / \mathrm{L} \text { ) }\end{array}$ & 1.51 & 1.24 & $2.11(\mathrm{H})$ & 1.35 & $0.62(\mathrm{~L})$ & NA & 1.17 & $I$ & 1.21 \\
\hline $\begin{array}{l}\text { Calcium (adjusted) } \\
\text { (range } 2.20-2.60 \\
\mathrm{mmol} / \mathrm{L} \text { ) }\end{array}$ & $2.03(\mathrm{~L})$ & $2.08(\mathrm{~L})$ & I.77 (L) & $2.16(\mathrm{~L})$ & 2.27 & NA & 2.39 & 2.37 & 2.44 \\
\hline $\begin{array}{l}\text { Bicarbonate } \\
\text { (range } 24-32 \mathrm{mmol} / \mathrm{L} \text { ) }\end{array}$ & $48(\mathrm{H})$ & $48(\mathrm{H})$ & 28 & 30 & 30 & 24 & 30 & 30 & 28 \\
\hline \multicolumn{10}{|l|}{$\begin{array}{l}\text { NA=Not Available } \\
\mathrm{H}=\text { High } \\
\mathrm{L}=\text { Low }\end{array}$} \\
\hline
\end{tabular}

Though commonly attributed to the rapid correction of hyponatraemia, there are case reports of central pontine myelinolysis in association with hypokalaemia, patients with anorexia nervosa when feeding is started, liver transplant patients, individuals undergoing dialysis and burns victims. ${ }^{5-9}$ Our patient did not have hyponatraemia but observing the electrolyte shifts during the admission, the central pontine myelinolysis occurred in conjunction with refeeding syndrome (see Table I). We suspect that the pontine and extrapontine regions may have been sensitive to the electrolyte shifts that occur in refeeding syndrome. Though central pontine myelinolysis is associated with a high mortality rate nearing 50 per cent (National Institute of Neurological diseases and stroke data) and most survivors are left with significant neurological deficits, our patient made a good functional recovery. The favourable factors contributing to the good outcome were concurrent treatment of all electrolyte disturbances, early Intensive Care Unit involvement at the advent of respiratory complications and also the early introduction of feeding including thiamine supplements, with close monitoring of the electrolyte changes with the involvement of the dietician.

\section{CONCLUSION}

Though commonly attributed to the rapid correction of hyponatraemia, there are case reports of central pontine myelinolysis in association with hypokalaemia, anorexia nervosa when feeding is started, patients undergoing dialysis and burns victims. ${ }^{1-5}$ This case demonstrates central pontine myelinolysis that occurred along with refeeding syndrome. A good functional recovery is possible. All patients at risk of developing refeeding syndrome should have their electrolytes closely monitored, including sodium, potassium, magnesium, glucose and phosphate. 


\section{REFERENCES}

I Mehanna H, Nanivelli PC, Moledina J et al. Refeeding syndrome awareness, prevention and management. Head Neck Oncol 2009, I:4. doi: I0. I I 86/1758-3284-I-4

2 National Institute for Health and Clinical Excellence [Internet]. Nutrition support in adults. Clinical guideline CG32 2006. [cited 20 II Jul 26]. Available from: http://www.nice.org.uk/nicemedia/ live/I0978/29978/29978.pdf

3 Adams RA, Victor M, Mancall EL. Central pontine myelinolysis: a hitherto undescribed disease occurring in alcoholics and malnourished patients. AMA Arch Neurol Psychiatry 1959; 81:154-72

4 Laureno R. Central pontine myelinolysis following rapid correction of hyponatremia. Ann Neurol 1983; 13:232-42. doi: 10. I002/ana.4I0I30303

5 Sugimoto T, Murata T, Omori M et al. Central pontine myelinolysis associated with hypokalemia in anorexia nervosa. J Neurol Neurosurg Psychiatry 2003; 74:353-55. doi: I0.I I36/jnnp.74.3.353
6 Patel AS, Matthews L, Bruce-Jones W. Central pontine myelinolysis as a complication of refeeding syndrome in a patient with anorexia nervosa.J Neuropsychiatry Clin Neurosci 2008; 20:37I-73. doi:I0.I I76/appi.neuropsych.20.3.37I

7 Kabeer MH, Filo RS, Milgrom ML et al. Central pontine myelinolysis following orthotopic liver transplant: association with cyclosporine toxicity.Postgrad Med J 1995;7|:239-4 I.doi: I0.I I 36/pgmj.7I.834.239

8 Tarhan TC, Agildere AM, Benli US et al. Osmotic demyelination syndrome in end-stage renal disease after recent hemodialysis: MRI of the brain. AJR AM J Roentgenol 2004; 182:809-16.

9 McKee AC, Winkelman MD, Barker BQ. Central pontine myelinolysis in severely burned patients: relationship to serum hyperosmolality. Neurology 1988; 38: 121 I-17.

* An error was identified after this issue was printed ('signal in the central pons myelinolysis' has been corrected to 'signal in the central pons'. This correction was made 26 September 2011.

\section{CONFERENCING AND EVENTS}

The Royal College of Physicians of Edinburgh has a unique blend of rooms providing the perfect location for your conference, meeting or event. The Victorian Great Hall, galleried New Library and the Georgian Cullen Suite are wonderful settings for dinners and receptions. The modern Conference Centre seats up to 300 people in raked seating and is complemented by breakout rooms seating from 10 to 150 people, a keypad voting system and video conferencing. The College provides a stunning setting for weddings and receptions and is licensed for both civil and religious ceremonies. Discounts are available for Fellows and Members, medical conferences and charities.

For more information or for a quotation, please contact the Events Team on +44 (0) I 3 I 225 7324; email events@rcpe.ac.uk or visit http://www.rcpe.ac.uk/conferencing/index.php

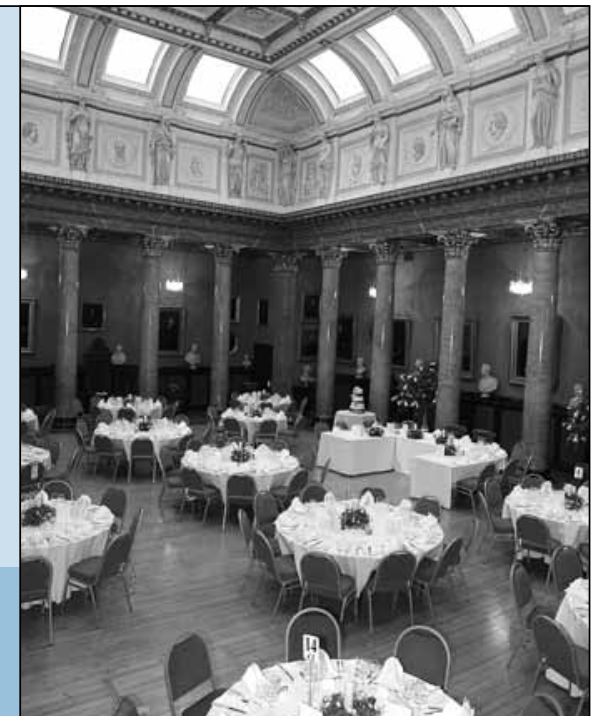

